evidence of occasional attacks of bronchitis. With regard to treatment, there was the old story : an infinity of remedies had been tried, and, with a single exception, nothing had done him any permanent good. That exception was chloroform, which never failed to give immediate relief. On waking each morning with his usual attack, from half a drachm to a drachm was inhaled. The difficulty of breathing at once subsided, the patient went off into a tranquil sleep, and there was an end of it; whereas, if the chloroform was not given, the dyspnoea would go on increasing, become very tedious, and very likely culminate in a regular attack. But with this single exception, all remedies that had been tried appeared inert. Several things that had not been employed I made a trial of, but with an equally unfavourable result till I tried iodide of potassium. The effect of this was very soon shown. No severe attack occurred after it was commenced, and in a few days the regular morning attacks ceased also. The patient now slept all night without disturbance, and there was no longer any necessity for resorting to the chloroform. This went on for six weeks; the iodide of potassium was then left off. In a few days the asthma began to show itself again, and in a week or two was as bad as ever. The iodide was then resumed, with the same beneficial results as before. I have not heard of this patient now for more than a month; and this very circumstance inclines me to hope that this remedy still keeps his enemy at bay.

It should always be borne in mind, in giving iodide of potas. sium for asthma, that it is often some time before it begins to take effect. I have a patient at the present time under my care who has been taking it for three weeks past in eight.grain doses three times a day, but it is only during the last week that any decided improvement has taken place in him. He has lost his spasms; the expectoration has very much decreased; and he has ceased to experience an abiding "thickness" and tightness of breathing that he had in the intervals of the attacks, and which never left him. His nurse tells me that whereas before, for months past, whenever he was asleep his breathing was audible and laboured, and accompanied with a slight wheezing, it is now inaudible and tranquil. Yet for the first fortnight this patient derived no apparent benefit whatever from the drug, and was anxious to give it up; now, however, he is convinced of the good it is doing him, and is anxiuus to continue it. It may be asked, Why do I think that the improvement is really to be assigned to a remedy that seems to remain so long inoperative? Why may not the apparent benefit be a coincidence, and the drug be really doing him no good whatever? I think the improvement is the work of the iodide for two reasons. In the first place, from the fixedness of the patient's previous condition for a great length of time, no meảicines or any other agencies that were brought to bear upon him making any difference in him. In the second place, from this tardiness of the action of the iodide of potassium corresponding with its action in other affections. How long is it, for instance, before it makes any appreciable impression upon a goltre, how ever complete and satisfactory its results may ultimately be !

I used to think that the benefit derived from iodide of potassium in asthma was entirely due to its beneficial influence in chronic bronchitis, and therefore that the only cases of asthma in which it did any good were cases in which chronic bronchitis and asthma coexisted, and the one was the exciting cause of the other. I am compelled, however, now to abandon that view; for in some of the cases in which its efficacy has been the most striking there has not been a trace of bronchitis.

Another theory that I once held I am also obliged to abandon -namely, that it was of advantage only in those cases in which the asthma was due to a gouty or rheumatic-gouty condition; and that it was by relieving this condition that it relieved the consequent asthma. In two of the cases that I have related this view would be borne out, for there was evidence of gout in both of them; but in the third there was not a trace. Moreover, I have seen cases of true gouty asthma in which iodide of potassium has been ot no service.

Of its ultimate and exact modus operandi I can neither offer any explanation nor form any reasonable opinion. I am not, however, the less satisfied of its occasional great value, and of the propriety of its use in any case in which it has not been tried.

Montazue-street, Russell-square, Jan. 1864.

Norfolk and NoRwich Hospital.-The Council of the Usiversity of London have decided on receiving certificates of attendance on hospital practice and chemical instruction from the Norfolk and Norwich Infirmary for the purposes of graduation in medicine.

\section{ON TRICHINA SPIRALIS.}

\author{
Bx W. MÜLLER, M.D., Homburg.
}

For many years past the Trichina spiralis (class Nematodes) have been found in the muscles of hogs, wound up in a spiral form, and enclosed in chalky capsules; and Dr. Owen discovered and described them in the muscles of men. Professor Zenker, of Dresden, was the first who proved, by a full and exact statement of a case, and a careful and minute postmortem examination, that the development and wandering of the trichinæ in the human body produce violent symptoms similar to those of typhus fever, and cause, most probably, in many cases, the death of the individual.

Experiments made by Professor Virchow, ${ }^{*}$ of Berlin, and Professor Leuckart, of Giessen, by feeding animals with pork in which were trichinæ, proved the same as Professor Zenker's observations in the above-mentioned case-namely, that the trichinæ, when taken into the stomach, commence almost immediately their development, male and female, and innumerable embryons. The young worms, perforating the intestines, enter the muscles, and, wandering in them, produce the violent symptoms of the disease above mentioned, until they become incapsulated in the muscles, in which state they are innocuous.

In Hettstaedt, a small town in Prussia, containing about 5000 or 6000 inhabitants, a veritable epidemical propagation of trichinæ commenced in the middle of October last, in consequence of the infected persons having eaten a kind of sausage (not thoroughly cooked) made of pork in which were trichinæ.

In some cases small portions of muscles were taken by Middeldorpf's harpoon from the persons infected, and whilst suffering with the disease; and by submitting those portions to microscopical examination trichinæ were discovered in them.

In the evening of the 9 th of November last I was summoned by a telegram from the physician of Hetistaedt, informing me that a relation of mine was suffering from the trichina disease; that he had also a pneumonic affection, and was very ill. On my arrival on the following day I found the patient-who previous to the attack was a strong and very healthy man, twenty. three years of age-perfectly conscious, with a slight œdematous swelling of the face. On examination of the chest, a dull sound over about an inch and a half of the lowest part of the lower lobe of the left lung was produced by percussion ; crepitating rattles were audible, but there was no bronchial breath. ing, thus showing the beginning of resolution of the pneumonia; at the lowest part emitting the dull sound there was a slight pleuritic rubbing. The pulse was 140 ; respirations 48 ; and the temperature of the body $39^{\circ}$ centigrade.

The symptoms of the disease commenced on the $16 \mathrm{th}$ of October with loss of appetite and diarrhoea, followed by a sensation of painful weakness in the limbs and difficulty in moving the tongue; the pulse being above 100 . The patient was not confined to his bed during the day-time until the 6th of November, when the pneumonic symptoms commenced.

The day after my arrivall (Nov. 1 (th) the pneumonic symptoms were unaltered, with the ex reption of the pleuritic rubbing, which had moved a little higher up. The whole of the pleuro-pneumonic affection was so very trifling that it certainly did not account for a pulse of from 140 to 150 , and for the violent oppression, or rather, as the patient explained it himself, " the weakness in drawing his breath."

The following day the frequency of respiration varied between 30 and 60 ; the pulse was more than 200 , and very weak; the temperature had fallen to $38^{\circ} 6^{\prime}$ centigrade; and the body was covered with a profuse clammy perspiration. The other phy. sical symptoms were the same as before, and the pleuritis had not extended bigher. The complaint of weakness in breathing, or, as the patient called it, "the impossibility of drawing a sufficient quantity of air into the lungs," was increased; but he remained conscious and resigned, so much so that he several times asked me at what hour I expected he would die.

At seven o'clock on the evening of the 12th of November he died.

The post-mortem examination, performed on the 13th, proved an infiltration of a part of the lower lobe of the left lung, extending upwards ahout an inch and a half from the lower margin of the lung, and about three or four ounces of liquid exudation in the pleural cavity of the same side. When examining the 
chest and intercostal muscles, I found, in every small piece of the muscle placed under the microscope, trichinæ partly wound up, but not capsulated, partly forming a single sling, and partly extended. In the examined parts of the heart and diaphragm no trichinæ were discovered.

On the day previous to the above-mentioned post-mortem examination $I$ examined with the microscope several small pieces of muscles, which had been taken from the bodies of persons who had lied of the disease, and were given to me by the physician of Hettstaedt, Dr. Rupprecht, and I found a considerable number of trichinæ in them.

Previous to my departure from Hettstaedt, eighteen to twenty persons had died of the trichina disease, and more than eighty persons were at that period afflicted with the same malady, produced by the same cause.

According to the information 1 obtained on the spot, the disease begins, a few days after eating the meat in which there were trichinæ, with loss of appetite, and almost without exception with diarrhcea and fever; cedema of the eyelids; also pain, or at least painful sensation of weakness, in the limbs; œdema of the joints; difficulty in moving the tongue; profuse clammy perspiration : and those patients who do not become convalescent, die either unconscious with symptonas of typhus fever, or, in a few cases, remain conscious to the end, complaining of inability to breathe freely.

The only important symptom of typhus absent in the disease is the enlargement of the spleen, and it is very probable that some of the so-called epidemics of typhus fever in former days were caused by the propagation of trichinæ in the human body.

Since the disease has been known (about three years ago) a great many cases have been observed in Germany.

The vitality of the trichinæ is not destroyed unless the meat or other substances in which they are located be subjected to the temperature of boiling water for a sufficient time to ensure that every particle has been acted upon by that degree of heat. Salting and smoking trichinous meat, as is usually done, does not appear to be sufficient to destroy the worms in all parts of the meat.

Picric acid (acidum picro nitricum) was tried with the hope that it might be administered with success to the patient, but it failed.

In trichinous pork of a pig killed with picrin acid, the worms were found alive.

Homburg, December, 1863.

\section{d e}

OF THE PRACTICE OF

\section{MEDICINE AND SURGERY IN THE}

\section{HOSPITALS OF LONDON.}

Nulla autem est alia procerto noscendi via, nisi quamplurimas et morborum, et dissectionum historias, tum aliorum, tum proprias collectas habere, et inter se comparare.-Moвgagir De Sed, et Caus. Morb., lib. ir. Proomium.

\section{ST. THOMAS'S HOSPITAL.}

BAD CASE OF SUICIDAL CUT-THROAT, BETWEEN THE HYOID B INE AND THYROID CARTILAGE; H FMORRHAGE; RECOVERY.

(Under the care of Mr. SolLY.)

THE details of the following case, kindly furnished by Mr. Henry Summerhayes, the house-surgeon, speak for themselves, and show what perseverance and care will do even in almost hopelessly bad cases. The plan adopted for feeding and supporting the strength of the patient cannot be too highly commended.

T. $\mathbf{M}-$, a tailor, aged twenty-two, was admitted at halfpast eleven A.M. on October 20th, 1863. It appeared from the account given by his friends that he had made the attempt on his life some thirty or forty minutes previous to admission, and had lost an immense quantity of blood. He was blanched, pulseless, cold, and insensible. On removing the towels that had been wrapped round his neck the wound was discovered, deep and clean, comprising the space betwixt the common carotid arteries at their point of bifurcation, quite transverse, passing between the hyoid bone and the thyroid cartilage, and dividing the larynx completely, as well as three-fourths of the pharynx; the epiglottis also was cut through. Some large clots of blood were cleared away from the wound and its edges, after which the carotids could be seen, pulsating very feebly, at the exact margin of the wound on either side. On attempt. ing to introduce a large cesophagus tube by the mouth profuse venous hæmorrhage came on, which was soon checked by pressure with a sponge dipped in iced water. No bleeding point could be detected. On cessation of the hromorrhage, a smaller tube (size of No. 10 catheter) was passed by the mouth, and two eggs beaten up with two ounces of brandy injected through it. This rallied the patient somewhat; but half an hour sub. sequently violent retching and sickness came on, some of the vomit being ejected through the wound; the venous hæmorrhage returned, and was checked with greater difficulty. Two enemata were thrown up, but were rejected at once. The tube that had been passed by the mouth was then inserted by way of the left nostril and retained there, for the constant exhibition of liquid food, brandy, arrowroot, \&c. He was placed on his back with a small pillow under his neck, and the wound gaping, so that in the event of hæmorrhage arising on the return of a stronger circulation any arterial point found bleed. ing might be seized at once and tied. In a few hours much hæmorrhage came on, and the anterior jugular vein of the left side was tied at both ends where it was found cut. As the vomiting continued whenever food was given, he was ordered to be fed often and in minute quantities. The plan was fairly successful. He remained insensible far into the night, and was placed under the constant watch of a dresser.

Oct. 27th - A little colour in cheeks ; fully conscious ; pulse able to be counted, 130, weak; sickness no longer troublesome, though not completely checked; has had some sleep. Food given every twenty minutes. He was ordered twelve ounces of brandy and eight eggs daily ; ice to suck. - Evening: Pulse stronger, 120 ; a good deal of thin mucus flowing from the wound ; patient kept completely screened in, so as to be preserved from draught as much as possible; position unchanged; wound covered with a piece of muslin.

28th.-Pulse 110, stronger; has been sick three or four times to.day; much frothy mucus about the wound.

29th.-Pulse 110, weaker; has had a good night; tube taken out from left nostril, and a second passed by right, as the first was giving some pain; a great quantity of frothy and sticky mucus issues from wound, but the respiration is as yet unaffected.

30th. - The same, but is very peevish and troublesome, want. ing his lips to be constantly moistened.

31 st. - Better ; pulse stronger, 166.

Nov. 1st. - Tube changed back to left nostril ; pulse 120 , rather weaker.

2nd.-Has slept a good deal during the night; is quieter than he was; no chest symptoms; much sticky mucus about the wound; pulse 120 ; dresser's watch abandoned.

10th. - Has gone on tranquilly; has had some pain in the chest, with other signs of bronchial inflammation; not so much mucus discharged by the wound; pulse 96 .

$24 \mathrm{th}$. - Fresh tube in left nostril; edges of wound healthy; granulation and contraction; not so much discharge; some union of pharynx from behind forward; none of larynx.

28 th. - Has gone on well since last report; still much mucus from the wound. An attempt to swallow food by the mouth failed, the food passing out by the wound, and causing much irritation; pulse quiet, weak, 80 .

Dec. 5th. - Lips of wound nearly closed ; cannot pass finger into pharynx; no union of larynx; takes his food without much difficulty; can speak so as to be well understood, though in a hoarse and croaking manner. His diet was gradually changed-the excessive stimulants dropped, and solid food, meat, \&c., given instead; and on the $28 \mathrm{th}$ he was discharged, with little deformity left. Still a small central hole leading into larynx, and thence into pharynx (probe size); thyroid cartilage very prominent; some difficulty in swallowing large solid pieces of food; liquids pass sometimes the "wrong way," and a few drops may show at the external aperture ; most inconvenience when his head is upright; accordingly he walks with his head a little bowed; is pale, but moderately strong; voice natural; no cough. 